4. Способ переработки отходов калийного производства: пат. 2497961 Рос. Федерация: МПК С 22 В 11/00 (2006.01), С 22 В 7/00 (2006.01) / Сметанников А.Ф., Оносов Д.В., Синегрибов В.А., Косолапова А.И., Новиков П.Ю., Семенов А.А.; патентообладатель ГИ УрО РАН. - № 2012142039/02. заявл. 02.10.2012; опубл. 10.11.2013.

5. Методы анализа рассолов и солей / под ред. Ю.В. Морачевского и Е.М. Петровой. - 2-е изд., перераб. и доп. - М.; Л.: Химия, 1964. - 403 с.: ил.

6. Капиллярно-электролитический способ извлечения микро-и наночастиц соединений металлов из тонких фракций горных пород, руд и техногенных продуктов: пат. 2659871 Рос. Федерация: МПК В 82 В 3/00 (2006.01) / Сметанников А.Ф., Оносов Д.В.; патентообладатель: ПФИЦ УрО РАН. - № 2016150221. заявл. 20.12.2016; опубл. 04.07.2018. - Бюл. № 19.

7. Способ подготовки проб нерастворимого остатка соляных пород и продуктов их переработки для качественного и количественного определения содержания благородных металлов: пат. №2347206 Рос. Федерация: МПК G 01 N 1/28 (2006.01) / Сметанников А.Ф., Синегрибов В.А., Логвиненко И.А., Новиков П.Ю., Седых Э.М., Шанина С.Н., Красноштейн А.Е; заявитель и патентообладатель ЗАО «Уралкалий-Технология». - № 2007128507/28; заявл. 24.07.2007; опубл. 20.02.2009. - Бюл. № 5.

8. Способ качественного и количественного определения органических соединений благородных металлов в породах различного состава: пат. №2354967 Рос. Федерация: МПК G 01 N 30/06 (2006.01)/ Сметанников А.Ф., Серебряный Б.Л., Красноштейн А.Е; заявитель и патентообладатель ЗАО «Уралкалий-Технология». - № 2007134762/28; заявл. 18.09.2007; опубл. 10.05.2009. - Бюл. № 13.

9. Сметанников А.Ф., Оносов Д.В., Синегрибов В.А., Новиков П.Ю., Шанина С.Н. Благородные металлы в солях Верхнекамского месторождения и технология их извлечения // Горн. журн. - 2013. № 6. - C. 55-58.

\title{
ВЗАИМОСВЯЗЬ ЛИТОЛОГИИ И ГАЗОНОСНОСТИ СОЛЯНЫХ ПОРОД НА ПРИМЕРЕ ВЕРХНЕКАМСКОГО МЕСТОРОЖДЕНИЯ СОЛЕЙ
}

\author{
Д.Е. Трапезников, Е.П. Чиркова \\ Горный институт УрО РАН, г. Пермь
}

\begin{abstract}
Аннотация. В статье представлены результаты изучения литологии и газового состава чистых сильвинитов, глинистых сильвинитов и каменных солей. Чистые сильвиниты, имеющие малую примесь глины, характеризуются меньшим содержанием метана и пропана, но большим содержанием сложных углеводородов и широким размахом содержания азота. Глинистые сильвиниты содержат значительно больше метана и тяжелых углеводородов, но значительно меньше пропана и азота. Каменные соли характеризуются низкими содержаниями тяжелых углеводородов и высокими - азота.

Ключевые слова: Верхнекамское месторождение солей, газоносность, сильвинит, каменная соль, углеводороды.
\end{abstract}

\section{Введение}

На газоносность соляных пород влияет множество факторов, таких как литологический состав солей и подсолевых отложений, вторичные преобразования, вызванные диа-, катагенетическими и тектоническими процессами $[1,4]$.

В соляных породах выделяют свободный и связанный газ. Свободный газ локализован в глинистых прослоях, межзерновом пространстве и способен активно мигрировать в процессе тектонического или техногенного влияния на залежь. Считается, что он имеет полигенную природу [4]. К связанным газам относят включения в зернах солей, которые были захвачены кристаллом в процессе роста и перекристаллизации.

Верхнекамское месторождение солей расположено на территории Пермского края и в тектоническом отношении относится к Соликамской впадине Предуральского краевого прогиба [2]. Соляная залежь относится к иренскому горизонту кунгурского яруса (рис. 1). Морфологически залежь представляет собой овальную линзу мощностью бо- 
лее 400 м, которая состоит из четырех соляных толщ. Нижняя - подстилающая каменная соль (ПдКС) - сложена слоистой каменной солью с прослойками галопелитов, содержащих вкрапленность ангидрита, доломита. В приподошвенной части располагаются три мощных слоя (до 5 м) глин и мергелей. Над ПДКС располагается сильвинитовая зона (С3), образованная чередованием пластов сильвинитов (КрIII, KpII KpI, А) и каменной соли, а выше - карналлититовая зона (КЗ), в которой переслаиваются карналлитовые породы (пласты от Б до К) и каменная соль. Венчает соляную толщу покровная каменная соль (ПКС), которая также имеет слоистое строение и незначительное содержание доломита, ангидрита и глины.

Строение соляной залежи в целом довольно выдержанное, однако в пределах некоторых тектонических структур она может частично или полностью отсутствовать.

Перекрывают соляную толщу отложения соликамского горизонта уфимского яруса. Нижняя часть горизонта сложена мергелями (иногда доломитовыми) и содержит маломощные прослои каменной соли, в верхней части толщи подобные прослои в основном сложены гипсом.

\section{Методика}

В статье рассмотрены пробы соляных пород, отобранные в пределах горных выработок, которые пройдены в сильвинитовой толще и подстилающей каменной соли. В каждой пробе проводились исследования микроструктурных, минералогических и газовых компонентов. Пробы отобраны с двух ортогональных линейных выработок с шагом отбора в $100 \mathrm{м}$.

Первый профиль опробован по пласту КрII, где отобрано 30 проб (№ 1-30). Второй профиль опробован по подстилающей каменной соли, где взято 25 проб (№ 31-55).

Анализ состава связанных газов, полученных в ходе опробования, проводился на газовом хроматографе Varin Inc. CP-450 GC в ПНИПУ (аналитик О.В. Иванов).

Морфологические особенности и химический состав минералов, а также морфология полостей от газово-жидких включений исследовались на сканирующем электронном микроскопе (СЭM) VEGA 3 LMH (Tescan), укомплектованном системой рентгеновского энергодисперсионного микроанализа Oxford Instruments INCA Energy 250/X-max 20 в Горном институте УрО РАН (аналитик Е.П. Чиркова).

\section{Литология пород}

В рамках исследования сильвинитовые породы были разделены на две группы. Первые, относительно мономинеральные, с тонкими прослоями глины (до 5 см) и небольшим содержанием каменной соли, а вторые с крупными глинистыми прослоями (от 5 см).

Чистые сильвиниты (пласт КрII) это слоистые породы, состоящие из ритмично повторяющихся пакетов. Каждый пакет обычно сложен набором из черного слойка глины, слоя серого перистого и/или зернистого галита и слоя красного сильвинита (рис. 1.1а). На микроуровне сильвинит содержит рассеянные включения галита, цепочки и отдельные вростки ангидрита, редко - барит и обособления органики (рис. 1.1б, в). Внутри зерен сильвина отмечаются немногочисленные поры и более крупные полости, в т.ч. - с ангидритом и высолами галита и неотчетливой каймой, обогащенной бромом.

Глинистые сильвиниты (пласт KрII) - эти породы также состоят из слоя каменной соли и слоя красного сильвинита, но с более крупными (до 20 см) прослоями глины. В глинистых прослоях за счет деформации часто возникают трещины отрыва, которые заполняются волокнистым сильвином или галитом, т.е. формируются соляные жилы. В жилах галит представлен шестоватыми агрегатами длиной до 7 см, ориентированные перпендикулярно к стенкам жилы с обильной вкрапленностью красного гематита - основного красящего вещества сильвинитов (рис. 1.2 a). На микроуровне в жиле отмеча- 
ются согласные и несогласные реликты темно-красного сильвина, полости между индивидами и редкие, обозначающие проницаемые зоны, цепочки полостей внутри них. В галопелите отмечаются обширные участки, сложенные доломитом, а также включения органики и гнезда мелкого пирита (рис. 1.2 б, в).

Каменная соль (ПдКС) на макроуровне представляет собой каменную соль с прослоями глин. Каменная соль желтовато-серая, темно-серая неравномернозернистая средне-, крупнокристаллическая пологоволнистая, достаточно крепкая. У контакта с глиной структура кристаллов перистая, а выше - зернистая. Местами соль перекристаллизована до крупных и гигантских зерен (5-10 см).

На микроуровне в крупноперистой соли отмечены невзрачные полости на плоскостях спайности и локальные мелкопористые участки. Объемные же полости сопровождают галопелит и находятся на границе зерен. Галопелит содержит желваки ангидрита в гипсовой рубашке, доломит, пирит, ангидрит, барит, гипс, калиевые полевые шпаты и органику. В мелкоперистой соли полостей немного: в зернах - крупные полости на плоскостях спайности и хаотичные, иногда вытянутые по направлению спайности полости; между зерен - непостоянные и слабо выраженные пустоты (рис. 2.3б-г).

\section{Газово-жидкие включения}

Газово-жидкие включения (ГЖВ) в изученных пробах представлены как внутрикристаллическими, так и межкристаллическими разновидностями. Для изучения под сканирующим электронным микроскопом доступны только полости, в которых находились газово-жидкие включения.

Внутрикристаллические полости и ГЖВ, встреченные в изученных пробах, можно разделить на следующие разновидности.

1. Включения зон роста кристаллов характерны для перистого галита или шевронного галита. Эти ГЖВ концентрируются по граням кристалла галита в виде полос.

2. Включения, расположенные по плоскостям спайности.

3. Включения по трещинам (цепочечные).

4. Скрытые включения, проявляющиеся только под пучком электронов, в виде вскипающих участков в кристаллах галита.

Межкристаллические полости и ГЖВ расположены между кристаллами и одновременно они оставляют вмятины на гранях кристаллов в виде полостей, выемок, борозд и отпечатков разнообразной формы. Наиболее распространенными являются округлые, каплевидные, удлиненные и дактилоскопические формы.

\section{Структурные разновидности солей}

Изучение структурных и минералогических особенностей проб позволяют выделить 3 основные структурные разности солей: зернистая, директивная, полиэдрическая и их переходные разности.

Разнокристаллическая соль является первичной и наименее преобразованной, так как формируется только на мелководном дне эвапоритового бассейна. В изученных пробах встречаются два типа разнокристаллической соли: перистая и зернистая соль.

Для седиментационной каменной соли характерны скелетные кристаллы, обычно именуемые «перистой солью». В процессе роста кристаллов на дне бассейна за счет колебаний температуры рапы по граням кристалла скапливаются газово-жидкие включения. Включения имеют изометричную форму и небольшой размер.

Зернистая соль характерна как для каменной соли, так и для сильвинита. Она формируется за счет кристаллизации солей в толще рапы и их осаждения на дно бассейна. Для нее характерны внутризерновые полости разнообразной морфологии.

Объем связанных (внутризерновых) газов в разнокристаллических солях обычно больше, чем у других разностей, а газы имеют седиментационное происхождение. 


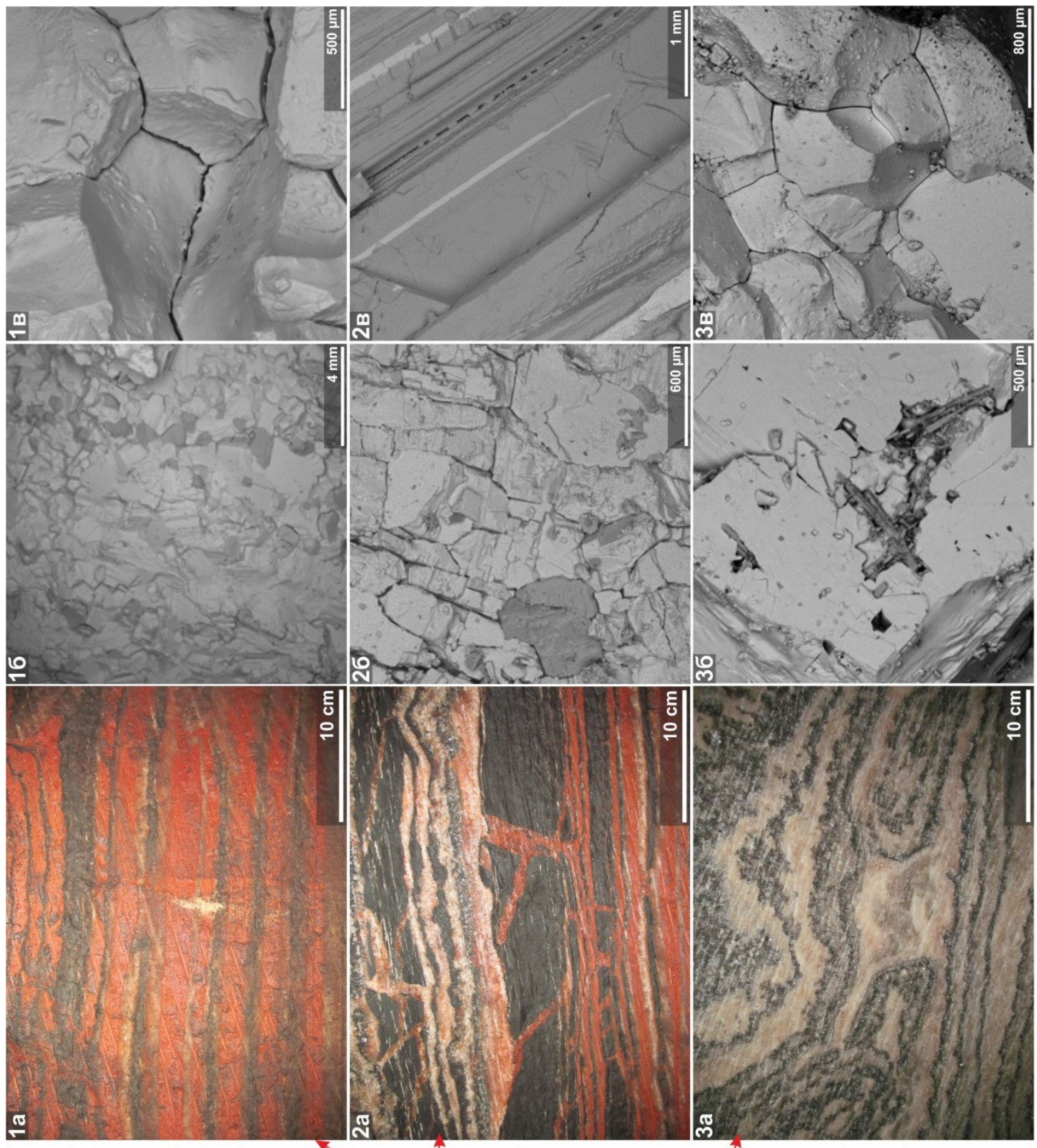

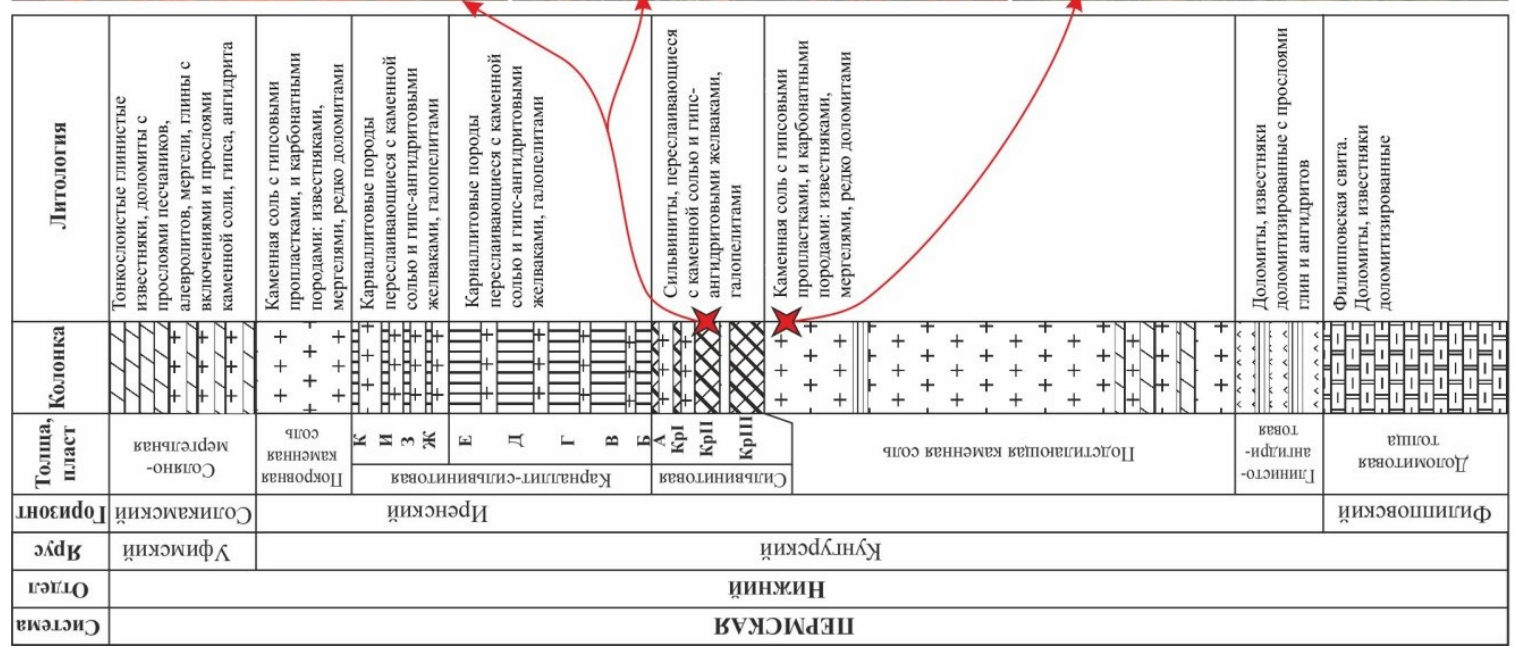

Рис. 1. Положение исследованных пластов на стратиграфической колонке и макро-, микрофотографии соляных пород из них 
Директивная соль сложена удлиненными кристаллами, ориентированными в одном направлении при тектонических напряжениях. Такая переориентировка и удлинение кристаллов вызывает медленное «течение солей». Деформация зерен под напряжением приводит к отжиманию газово-жидких включений вдоль плоскостей спайности, дислокационных зон и границ зерен. Межзерновые полости чаще имеют червеобразную форму, которая также указывает на медленное проскальзывание зерен относительно друг друга. Объем связанных газов в этих солях также высок и близок к объему зернистой соли.

Полиэдрическая соль встречается как в каменных солях, так и в сильвинитовых. Структура породы равномернокристаллическая с перекристаллизованными зернами изометричной полиэдрической формы. При этом гранные углы кристаллов стремятся к $120^{\circ}$, за счет чего образуются зерна гексагональной формы. Для этих пород характерен тусклый жирный блеск, вероятно, вызванный пленкой сорбированной воды. Межзерновые пространства имеют щелевидную форму. Порода легко крошится, так как зерна плохо связаны между собой. Объем связанных газов этих пород значительно ниже среднего уровня. Это связано с тем, что перекристаллизация влечет мобилизацию флюидной фазы и ее миграцию из зерен на их границы, что также приводит к уменьшению прочности пород.

\section{Газоносность соляных пород}

Методика определения газового состава позволяет определять только связанные (внутрикристаллические) газы. Поэтому данные химического анализа не отражают состав ГЖВ в открытых межзерновых пространствах. Как следствие, при такой методике не удается в полной мере установить влияние вторичных процессов на газовый состав пород.

Распределение общей газоносности связанных газов по всем пробам показало, что объем газов в сильвинитах и каменных солях принципиально не отличается и в среднем составляет порядка $0,046 \mathrm{~m}^{3}\left(\max -0,064 \mathrm{~m}^{3}, \min -0,012 \mathrm{~m}^{3}\right)$.

Среди всех газов доминирует азот, на который в каменных солях приходится порядка 97-99,5 \%, а в сильвинитах 78-96 \%. Оставшаяся часть приходится на углеводороды, водород и углекислый газ.

Среди углеводородов выделяются три группы: 1) метан и его простые гомологи; 2) изобутан и изопентан; 3) n-бутан и n-пентан. Соотношение этих групп газов хорошо демонстрируется на треугольной диаграмме (рис. 2a). Фигуративные точки сильвинитовых пород образуют линейно вытянутое поле, а каменных солей - изометричное. Это указывает на то, что в исследованных сильвинитах отмечается бо́льшая связь между содержанием легких углеводородов и изобутаном и изопентаном. В тоже время в каменных солях отмечается большее влияние n-бутана и n-пентана. На общем фоне резко выделяются глинистые сильвиниты, в которых значительно выше содержание изобутана и изопентана.

Соотношения горючих газов (метан + водород) с углеводородами (без метана) и углекислым газом (рис. 2б) достаточно четко отделяет литологические типы проб друг от друга. Прежде всего, резко разделились пробы глинистых сильвинитов, для которых характерно повышенное содержание тяжелых углеводородов. Это обусловлено повышенным содержанием глины, которая более благоприятна для накопления углеводородов с крупными молекулами. Сильвинитовые породы содержат меньше углекислого газа, чем каменные соли. В то же время последние содержат больше метана и водорода, чем тяжелых углеводородов.

Соотношение метана, водорода и углекислого газа (рис. 2в) показало широкий разбег по метану и углекислому газу. Содержание последнего может составлять до $50 \%$ от доли метана, а литологический состав пород в этом случае не имеет значения. Содержание водорода четко коррелируется с литологией. В каменных солях 
оно практически нулевое, немного выше (до 5\%) в глинистых сильвинитах, а заметная доля (5-10\%) отмечается лишь в чистых сильвинитах.

Зависимость между литологией пород и газовым составом четко прослеживается при сравнении соотношения метана и пропана. На графике (рис. 2г) глинистые сильв иниты резко выделяются по низкому содержанию пропана и более высокому - метана. Сильвиниты и каменные соли имеют близкий уровень содержания метана, но в каменных солях содержание пропана и метана в целом выше.

Соотношение суммы углеводородов и суммы горючих газов (метан и водород) также демонстрирует четкую зависимость между литологией пород и газовым составом (рис. 2д). Но при введении дополнительного параметра - величины содержания азота, наблюдается другая зависимость. Чем выше содержание углеводородов, тем ниже содержание азота.

Глинистые сильвиниты значительно выделяются на фоне остальных пород более высоким содержанием тяжелых углеводородов, высоким содержанием азота и более низким уровнем горючих газов.

Сильвиниты выделяются по большему содержанию углеводородов и образуют линейное поле. Большой размах между пробами сильвинитов обусловлен широким размах содержания азота (от 79 до 99\%).

Каменные соли имеют высокое содержание азота, порядка 97-99\%, за счет чего поле точек более компактное по сравнению с сильвинитами (график представлен в логарифмическом масштабе). Каменные соли имеют низкий уровень как тяжелых углеводородов, так и горючих газов.

\section{Заключение}

Изучение литологии и состава связанных газов соляных пород Верхнекамского месторождении солей позволило установить следующие закономерности. Сильвиниты, имеющие малую примесь глины, отличаются меньшим содержанием метана и пропана, но большим содержанием сложных углеводородов и широким размахом содержания азота. Глинистые сильвиниты содержат значительно больше метана и тяжелых углеводородов, а пропана и азота значительно меньше. Каменные соли характеризуются низкими содержаниями тяжелых углеводородов и высокими - азота.

Анализ структурных и минералогических особенностей проб позволил выявить три структурных разности солей: зернистую, директивную, полиэдрическую. Каждая из разностей характеризуется определенным набором типов газово-жидких включений, морфология и структурная позиция которых зависит от процессов перекристаллизации.

\section{Работа выполнена при финансовой поддержке гранта РФФИ № 18-05-00046.}

\section{БИБЛИОГРАФИЧЕСКИЙ СПИСОК}

1. Андрейко С.С., Галкин В.И., Шаманский Г.П. Некоторые особенности распределения углеводородных газов по разрезу Верхнекамского месторождения калийных солей // Разработка соляных месторождений: межвуз. сб. науч. тр. / ППИ. - Пермь, 1980. - С. 82-87.

2. Кудряшов А.И. Верхнекамское месторождение солей / ГИ УрО РАН; [отв. ред. В.И. Раевский]. Пермь: [Соликам. тип.], 2001. - 429 с.: ил.

3. Чайковский И.И., Одинцова Т.А., Иванов О.В. О зональном распределении органического вещества в одной из зон эпигенетической трансформации солей на Верхнекамском месторождении // Горное эхо. - 2012. - № 3 (49). - С. 29-32.

4. Чайковский И.И. Тектонический контроль зон разубоживания на Верхнекамском месторождении солей // Стратегия и процессы освоения георесурсов: сб. науч. тр. Вып. 11 / ГИ УрО РАН. - Пермь, 2013. - C. 3-5. 

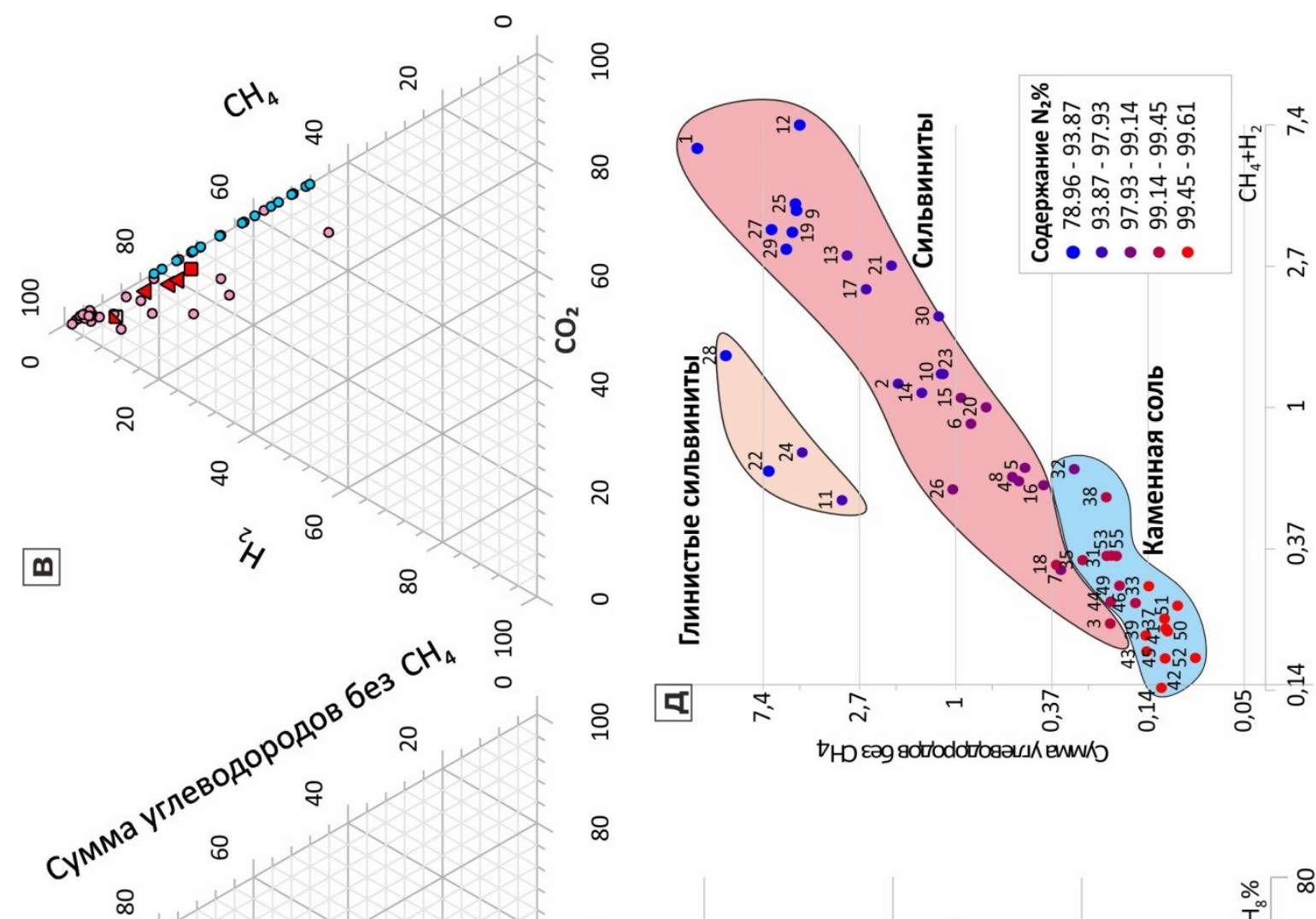

$\infty$
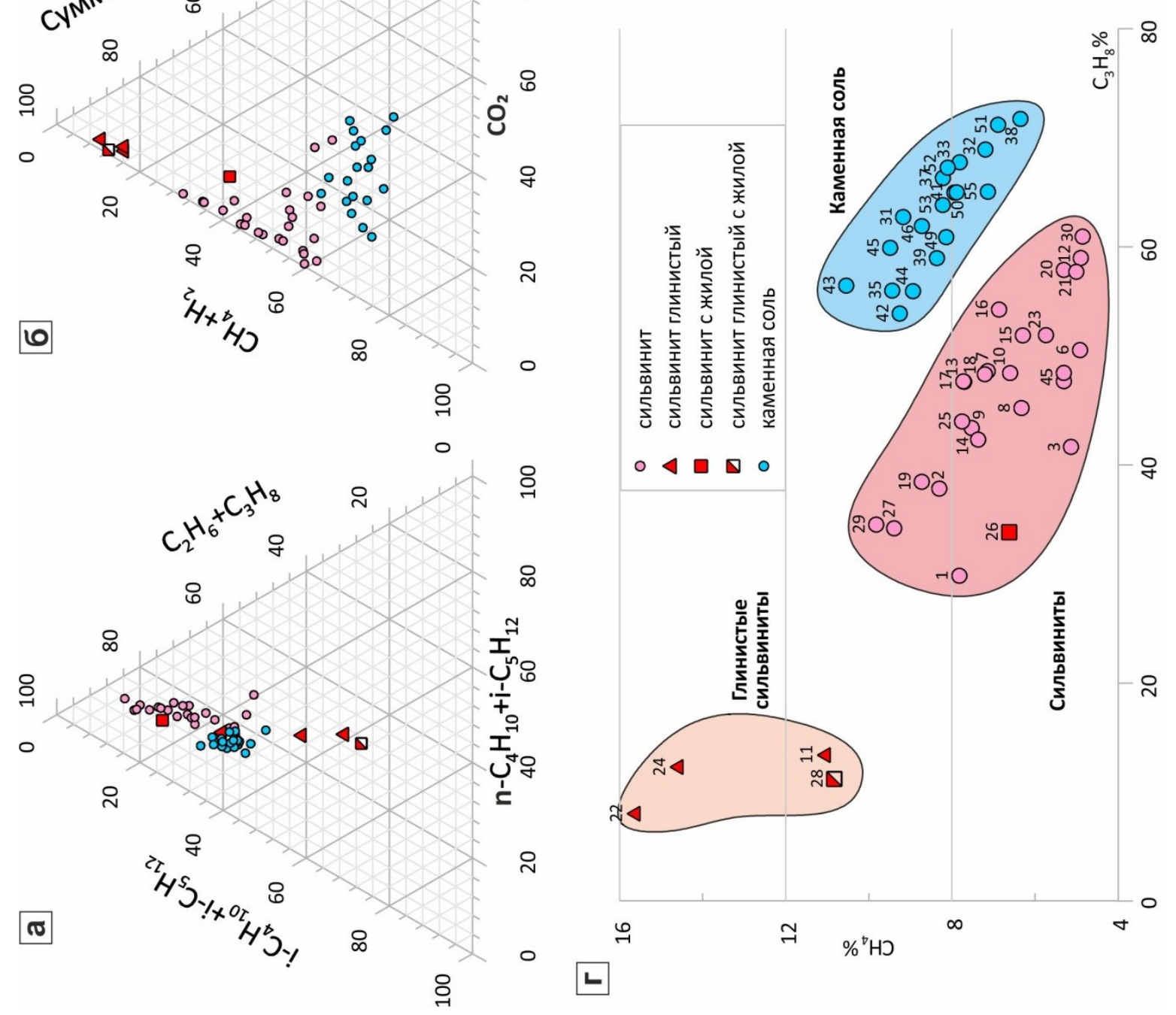

Рис. 2. Диаграммы соотношения вещественных компонентов связанных газов в исследованных соляных породах 